\title{
A Study of Ease of LMA Supreme Insertion
}

\author{
Pramod Bhale ${ }^{1}$, Mitalee Pareek ${ }^{2}$, Apurva Deshmukh ${ }^{2}$, Sanhita Kulkarni ${ }^{1}$ \\ ${ }^{1}$ Professor, ${ }^{2}$ Resident, Department of Anaesthesia, MGM Medical College, Aurangabad, Maharashtra, India
}

\begin{abstract}
:-
\section{$>$ Background and Aims-}

This randomized, open label experimental study was undertaken to observe the ease of insertion, time taken for insertion of LMA supreme and ease of gastric tube insertion.
\end{abstract}

\section{$>$ Methods-}

Thirty adult patients undergoing elective surgery under general anaesthesia were assessed. Ease of insertion of LMA supreme and Gastric Tube was assessed with number of attempts required for insertion. Time taken for insertion and post-operative side effects of LMA supreme insertion were also observed.

\section{$>$ Results-}

The demographic profile of patients was comparable. In our study out of 30 patients, LMA supreme was inserted in first attempt in $27(\mathbf{9 0 . 0 0 \%})$ patients, only $3(10.00 \%)$ patients required second attempt. Mean time taken for insertion of LMA supreme was 7.30 \pm 3.03 seconds. Gastric tube insertion was Easy in $29(96.7 \%)$ and Impossible in $1(3.33 \%)$. Hemodynamic response to insertion were similar in all patients and adverse effects were not significant.

\section{Conclusion-}

The LMA supreme takes 8 seconds for insertion, with post-operative sore throat in $1(3.33 \%)$ patient after 24 hours of surgery. LMA supreme can be considered as preferred choice of airway for elective surgeries under general anaesthesia.

Keywords:- Supraglottic Airways, LMA Supreme, General anaesthesia.

\section{INTRODUCTION}

Supraglottic airway devices (SAD) have been the standard fixture in airway management. (1) It conveniently and effectively fills the bridge in securing airway between tracheal intubation and use of face mask. It has the advantage of being less traumatic and effortless insertion, without the necessity for laryngoscopy. (2)

Laryngeal mask airway classic is a first generation supraglottic airway device, originally developed by Dr. Archie Brain in 1981. (3) The introduction of laryngeal mask airway (LMA) marked landmark advancement in airway management. (4) In 1996 LMA even gained entry into the American Society of Anaesthesiologists (ASA) difficult airway algorithm. (5)
First generation supraglottic airway devices provide little protection against gastric regurgitation and aspiration. Newer devices have incorporated designed elements to minimize this risk. They provide higher airway leak pressure (6) than the classic LMA and can be used for spontaneous as well as positive pressure ventilation.

The LMA supreme airway is a novel device having an inflatable anatomical seal of the pharyngeal, laryngeal and peri-laryngeal structures. (6). They have a passage for gastric tube insertion which can be used for gastric deflation and due to this advantage; use of these devices has been increased over a decade.

Here, we have observed the ease of insertion, time taken to insert and post operatively occurring side effects of LMA supreme along with ease of insertion of gastric tube .

\section{MATERIALS AND METHODS}

A randomized, open label experimental study was conducted in 30 patients in Department of Anesthesia in MGM Hospital, Aurangabad over a period of two years from November 2016 to September 2018 after approval from ethical committee.

Patients aged between 18-60years with MPC (Mallampatti Classification) grade I and II and accepted under ASA grade I and II for elective surgeries under general anaesthesia were included in the study. Patients with MPC grade III and IV or mouth opening $<2 \mathrm{~cm}$, history of URI or BMI $>35 \mathrm{~kg} / \mathrm{m} 2$ and any abnormality of the neck were excluded form the study.

Materials used were LMA supreme number 3 and 4, water based lubricant jelly and 10 and 12 Fr gastric tube for LMA no 3 and no 4 respectively. A written informed consent was obtained from all patients before including them in the study.

Patients were kept NPO (nil per oral) for 6 hours prior to surgery. All patients were advised Tablet Alprazolam0.5mg and Tablet Omeprazole $40 \mathrm{mg}$ orally at night before surgery. The size of the device was decided based on patient's body weight and standard recommendation(1)

Group-LMA SUPREME- size 3:- for patients weighing between $30-50 \mathrm{~kg}$,

Size 4 :- for patients between $50-90 \mathrm{~kg}$. 
Intravenous(IV) Line was secured with angiocath number 20 gauge. Preoperative baseline parameters like Pulse rate, Mean arterial pressure, SPO2 were noted.

All patients received Inj.Glycopyrrolate $0.005 \mathrm{mg} / \mathrm{kg}$ IV, Inj. Midazolam $0.05 \mathrm{mg} / \mathrm{kg}$ IV and Inj.Fortwin $0.5 \mathrm{mg} / \mathrm{kg}$ as premedication. After 3 minutes of preoxygenation, General anaesthesia was induced by Inj.Propofol $2 \mathrm{mg} / \mathrm{kg}$. LMA supreme insertion was facilitated with Inj.Suxamethonium $(2 \mathrm{mg} / \mathrm{kg} \mathrm{IV})$. We waited for 45 seconds after giving i.v.Suxamethonium. A water-based jelly was applied to LMA supreme.

The anaesthesiologist inserted device from the head end of patient, while an assistant was opening jaw from the right hand side of the patient. We judged ease of insertion on the basis of number of insertion attempts. Number of insertion attempts was noted. When it was not possible to insert the device or ventilate through it, two more attempts of insertion were allowed. If placement was failed after three attempts, the procedure was abandoned and this case was considered as a failed attempt. Endotracheal intubation was performed and case was excluded from the study. Time of insertion was noted from the time the operator picked up LMA supreme till the ventilation was established. We clinically judged adequate ventilation by chest rise and minimal leak.

Hemodynamic responses (HR,MBP,SPO2) were recorded at the time of insertion of device i.e. 0 minute and then at 1, 3,5,10,15,20 minutes after insertion of LMA supreme. Anaesthesia was maintained with isoflurane in oxygen and nitrous oxide (50\%-50\%). Atracurium in a dose of $0.5 \mathrm{mg} / \mathrm{kg}$ initial first dose and then $0.1 \mathrm{mg} / \mathrm{kg}$ for maintenance was given every $20 \mathrm{~min}$ to maintain muscle relaxation. Adequate IV fluids were given in the form of crystalloids.

Gastric tube of 10/12Fr was inserted through LMA supreme. Placement of gastric tube was confirmed by gastric content aspiration or by Woosh Test(8)(20ml air was pushed through gastric tube and a characteristic whooshing sound auscultated on epigastrium using diaphragm of stethoscope).

Grading of ease of insertion of gastric tube(10) (9)We divided ease of gastric tube insertion in three grades. O Grade1= Easy,

O Grade2=Difficult,

O Grade3=Impossible.

After completion of surgery, stomach was emptied and nasogastric tube was removed. Residual neuromuscular blockade was reversed with inj. Neostigmine $0.005 \mathrm{mg} / \mathrm{kg}+$ inj. Glycopyrrolate $0.001 \mathrm{mg} / \mathrm{kg}$. LMA supreme were removed when patient was obeying verbal commands. Patient was oxygenated for 10minutes after removal of device. Any visible blood staining on the LMA supreme was noted at removal. The lip, tongue, teeth were inspected for evidence of trauma in the immediate post-operative period. Incidence of sore throat, hoarseness and dysphagia was noted after 24 hours of surgery.
III. RESULTS

\begin{tabular}{|c|c|c|}
\hline \multirow{2}{*}{ AGE } & \multicolumn{2}{|c|}{ LMA supreme } \\
\cline { 2 - 3 } & No & Percentage \\
\hline$\leq 20$ years & 00 & 00 \\
\hline $21-30$ & 12 & $40.0 \%$ \\
\hline $31-40$ & 09 & $30.0 \%$ \\
\hline $41-50$ & 05 & $16.7 \%$ \\
\hline $51-60$ & 01 & $3.0 \%$ \\
\hline$>60$ & 03 & $10.0 \%$ \\
\hline Total & 30 & $100 \%$ \\
\hline Mean \pm SD & \multicolumn{2}{|c|}{$36.83 \pm \mathbf{1 2 . 5 4 7}$} \\
\hline
\end{tabular}

Table 1: Age of Patients

\begin{tabular}{|l|c|c|}
\hline \multirow{2}{*}{ GENDER } & \multicolumn{2}{|c|}{ LMA supreme } \\
\cline { 2 - 3 } & $\begin{array}{c}\text { No of } \\
\text { Patients }\end{array}$ & Percentage \\
\hline MALE & 27 & $90.0 \%$ \\
\hline FEMALE & 03 & $10.0 \%$ \\
\hline TOTAL & 30 & $100 \%$ \\
\hline
\end{tabular}

Table 2: Gender of Patients

\begin{tabular}{|l|c|c|}
\hline \multirow{2}{*}{ ASA GRADE } & \multicolumn{2}{|c|}{ LMA supreme } \\
\cline { 2 - 3 } & $\begin{array}{c}\text { No of } \\
\text { patients }\end{array}$ & Percentage \\
\hline GRADE 1 & 17 & $56.7 \% \%$ \\
\hline GRADE 2 & 13 & $43.3 \%$ \\
\hline TOTAL & 30 & $100 \%$ \\
\hline
\end{tabular}

Table 3: ASA Grade of Patients

\begin{tabular}{|c|c|c|}
\hline $\begin{array}{l}\text { NO OF } \\
\text { INSERTION } \\
\text { ATTEMPTS }\end{array}$ & \multicolumn{2}{|c|}{ LMA supreme } \\
\cline { 2 - 3 } & $\begin{array}{c}\text { No of } \\
\text { patients }\end{array}$ & Percentage \\
\hline 1 & 27 & $90.0 \%$ \\
\hline 2 & 03 & $10.0 \%$ \\
\hline TOTAL & 30 & $100 \%$ \\
\hline
\end{tabular}

Table 4: Number of Insertion Attempts 


\begin{tabular}{|l|l|l|}
\hline $\begin{array}{l}\text { EASE OF } \\
\text { GASTRIC } \\
\text { TUBE } \\
\text { INSERTION }\end{array}$ & \multicolumn{2}{|c|}{ LMA } \\
\cline { 2 - 3 } & $\begin{array}{l}\mid 2 \\
\text { No of } \\
\text { Patients }\end{array}$ & Percentage \\
\hline EASY & 29 & $96.7 \% \%$ \\
\hline DIFFICULT & 00 & 00 \\
\hline IMPOSSIBLE & $\mathbf{0 1}$ & $3.33 \%$ \\
\hline TOTAL & 30 & $100 \%$ \\
\hline
\end{tabular}

Table 5: Ease of Gastric Tube Insertion

\begin{tabular}{|l|l|l|}
\hline \multirow{2}{*}{$\begin{array}{l}\text { ADVERSE } \\
\text { EFFECTS }\end{array}$} & \multicolumn{2}{|c|}{ LMA supreme } \\
\cline { 2 - 3 } & $\begin{array}{l}\text { No of } \\
\text { patients }\end{array}$ & Percentage \\
\hline Sore throat & 01 & $3.3 \%$ \\
\hline $\begin{array}{l}\text { Tongue, Lip } \\
\text { Trauma }\end{array}$ & 00 & 00 \\
\hline None & 29 & $96.7 \% \%$ \\
\hline Total & 30 & $100 \%$ \\
\hline
\end{tabular}

Table 6: Adverse Effects

\section{DISCUSSION}

LMA supreme is a second generation supraglottic airway device. It has a passage for gastric tube insertion which can be used for gastric deflation.

In our institute, we routinely use this device for surgeries under general anaesthesia and thus we have designed this study to observe insertion of LMA supreme. We selected 30 patients who were electively posted for surgery under general anaesthesia.

Primary aim of our study was to observe LMA supreme for ease of insertion i.e. number of attempts, time taken for insertion, hemodynamic changes, ease of insertion of gastric tube and adverse events like regurgitation, aspiration, tongue, lip or dental trauma, post-operative sore throat.

\section{A. Number of insertion attempts:-}

In our study out of 30 patients, LMA supreme was inserted in first attempt in $27(90.00 \%)$ patients, only 3 $(10.00 \%)$ patient's required second attempt.

\begin{tabular}{|c|c|c|c|c|c|}
\hline \multirow[t]{2}{*}{ SR.NO } & \multirow[b]{2}{*}{ STUDIES } & \multicolumn{4}{|c|}{$\begin{array}{l}\text { INSERTION SUCCESS ATTEMPTS (\%) IN LMA } \\
\text { SUPREME }\end{array}$} \\
\hline & & I & II & III & FAILED \\
\hline 1 & Theiler et ${ }_{\text {al }}(9)$ & 95 & 5 & 0 & 0 \\
\hline 2 & $\begin{array}{l}\text { Hyuk Kim et al } \\
\text { (12) }\end{array}$ & 98 & 2 & 0 & 0 \\
\hline 3 & $\begin{array}{c}\text { Vikas Gupta et al } \\
(10)\end{array}$ & 93.33 & 6.77 & 0 & 0 \\
\hline 4 & W.H.L. ${ }_{\text {Teoh }}(8)$ & 94 & 6 & 0 & 0 \\
\hline 5 & R.Ragazzi $_{\text {et al }}(11)$ & 77 & 13 & 10 & 0 \\
\hline 7 & OUR STUDY & 90 & 10 & $\mathbf{0}$ & $\mathbf{0}$ \\
\hline
\end{tabular}

In study of Theiler et al (9), LMA supreme group in 95\% patient's device was inserted in first attempt and 5\% patients required second attempt. This correlates with our study.

> In study of Hyuk Kim et al ${ }^{(12)}$, LMA supreme $98 \%$ of times device was inserted in first attempt and $2 \%$ patients required second attempt. No patient in their study required third attempt and there were no failures. This supports the result of our study.

$>$ In study of Vikas Gupta et al ${ }^{(10)}$, In $93.33 \%$ of patients in LMA supreme was inserted in first attempt, $6.67 \%$ patients' required second attempt. This correlates with result of our study.

> In study of Teoh W. H. L et al ${ }^{(8)}$, In LMA supreme group $94 \%$ of times the device was inserted in first attempt and $6 \%$ patients required second attempt. This supports the result of our study.
$>$ In study of R.Ragazzi et al ${ }^{(11)}$, In LMA supreme group $77 \%$ were inserted in first attempt, $13 \%$ required second attempt and $10 \%$ required third attempt. There were no failures for insertion. The results are not similar to our study because-

- An experienced anesthesiologist inserted SAD in our study, whereas in their study inexperienced people were inserting the device.

- We used inj. Succinylcholine $2 \mathrm{mg} / \mathrm{kg}$ for relaxation before insertion of devices but in their study they did not give relaxation for insertion of device.

B. Time taken for insertion:-

When compared to other studies, Mean time taken for insertion of LMA supreme was 7.30 \pm 3.03 seconds. 
ISSN No:-2456-2165

\begin{tabular}{|c|c|c|}
\hline SR.NO & STUDIES & $\begin{array}{c}\text { MEAN TIME TAKEN FOR INSERTION OF } \\
\text { LMA SUPREME }\end{array}$ \\
\hline 1 & Chew E.F.F. et $_{\text {al }}(14)$ & $20 \pm 5$ \\
\hline 2 & W.H.L. Teoh $(8)$ & 14.3 \\
\hline 3 & Theiler et al ${ }^{(9)}$ & $34 \pm 12$ \\
\hline 4 & Hyuk Kim et al (12) & $15.3 \pm 2.6$ \\
\hline $\mathbf{5}$ & OUR STUDY & $\mathbf{7 . 3 0} \pm \mathbf{3 . 0 3}$ \\
\hline
\end{tabular}

Table 8

Chew E.F.F. et al ${ }^{(14)}$, found out the mean insertion time for LMA supreme as $20 \pm 5$ seconds. The time of insertion in their study is longer than our study because-

- We used Inj. Succinylcholine $2 \mathrm{mg} / \mathrm{kg}$ in our study but they did not use relaxant in their study. They studied LMA supreme in spontaneously breathing adult patient.

W.H.L. Teoh (8), had a mean time of insertion of LMA supreme as 14.3 seconds. The time of insertion in their study is longer than our study because-

- They have used inj. Fentanyl 0.5 microgram $/ \mathrm{kg}$ IV for premedication in their study, whereas we used Inj. Pentazocin $0.5 \mathrm{mg} / \mathrm{kg}$ IV our study.

- They used atracurium $0.5 \mathrm{mg} / \mathrm{kg}$ for muscle relaxation in our study where as we used inj. Succinylcholine $2 \mathrm{mg} / \mathrm{kg}$ for relaxation before insertion of device in our study.

Theiler et al (9), the Median insertion time for LMA supreme was $34 \pm 12$ seconds. This dissimilarity in their study and our study can be because of use of different drugs.-

- They induced patients using inj. Fentanyl 1-3 microgram $/ \mathrm{kg}$ and inj. Propofol $2.5 \mathrm{mg} / \mathrm{kg}$, no muscle relaxation was used. We had used Inj. Pentazocin 0.5 $\mathrm{mg} / \mathrm{kg}$ as premedication, induction was done using Inj. Propofol $2 \mathrm{mg} / \mathrm{kg}$ and Inj. Suxamethonium (2mg/kg IV) was given for muscle relaxation. Good muscle relaxation facilitates insertion of supraglottic airway device which can be the reason for lesser insertion timing.

> Hyuk Kim et al (12), the Insertion time for LMA supreme was $15.3 \pm 2.6$ seconds. This dissimilarity between our study can be because of different techniques used for insertion and different drugs used for induction.-

- We used two people for insertion. One person was opening the jaw while the other person was inserting device, whereas a single person was inserting LMA supreme in their study.

- They have also used different drugs than our study. We used inj. Propofol $2 \mathrm{mg} / \mathrm{kg}$ for induction, whereas they have used inj. Ketamine $2 \mathrm{mg} / \mathrm{kg}$ for induction. They have used inj. Rocuronium $0.6 \mathrm{mg} / \mathrm{kg}$ IV as muscle relaxant, whereas we used Inj. Suxamethonium $2 \mathrm{mg} / \mathrm{kg}$ IV.

\section{Hemodynamic Parameters :-}

We recorded heart rate, mean arterial pressure(MAP) and $\mathrm{SpO} 2$ before induction (baseline) and then at 0 (at the time of insertion), 1, 3, 5,10,15,20 minutes after insertion of supraglottic airway device. There was no episode of desaturation.

\begin{tabular}{|c|c|c|}
\hline TIME & HR & MBP \\
\hline Pre insertion & $86.48 \pm 14.292$ & $89.14 \pm 11.874$ \\
\hline 0 Minute(at the time of insertion) & $86.97 \pm 14.244$ & $85.97 \pm 11.758$ \\
\hline 1Minute(after insertion) & $86.69 \pm 13.725$ & $83.41 \pm 12.480$ \\
\hline 3Minute(after insertion) & $86.10 \pm 15.214$ & $84.55 \pm 13.211$ \\
\hline 5Minute(after insertion) & $85.38 \pm 14.264$ & $84.90 \pm 11.353$ \\
\hline 10Minute(after insertion) & $85.00 \pm 14.609$ & $84.48 \pm 09.977$ \\
\hline 15Minute(after insertion) & $84.62 \pm 13.986$ & $86.28 \pm 12.032$ \\
\hline
\end{tabular}

Table 9

\section{Ease of gastric tube insertion :-}

In our study we divided ease of gastric tube insertion in three grades. Grade 1= Easy, Grade 2=Difficult, Grade $3=$ Impossible. It was Easy (grade 1) in $96.7 \%$ patients, difficult (grade 2) in $0.0 \%$ patients and impossible to insert (grade 3 ) in $3.33 \%$ patients. 


\begin{tabular}{|c|c|c|}
\hline \multirow[t]{2}{*}{ Ease of Insertion of Gastric Tube } & \multicolumn{2}{|l|}{ LMA supreme } \\
\hline & No & Percentage \\
\hline Easy & 29 & $96.7 \%$ \\
\hline Difficult & 00 & 00 \\
\hline Impossible & 01 & $3.33 \%$ \\
\hline Total & 30 & $100 \%$ \\
\hline
\end{tabular}

Table 10

\section{E. Adverse events:-}

Various complications of supraglottic airway devices are regurgitation, aspiration, trauma, dislodgement, postoperative sore throat, laryngospasm, nerve injuries, etc.

$>$ Regurgitation / aspiration-There was not a single case of regurgitation or aspiration in our study. All patients were elective, kept nil by mouth for $6 \mathrm{hrs}$. This might have reduced the chances of regurgitation.

$>$ Tongue / lip / dental trauma- In our study, NO patient had lip trauma.

$>$ Postoperative sore throat- In our study, 1 (3.33\%) patient developed sore throat when observed $24 \mathrm{hrs}$ after surgery.

> Hoarseness- We observed for hoarseness after $24 \mathrm{hrs}$ of surgery. It was not recorded in any of the patients.

$>$ Laryngospasm- We looked for perioperative laryngospasm (from induction till 30 mins after extubation). There was no incidence of laryngospasm in any patient.

\section{CONCLUSION}

The LMA supreme takes 8 seconds for insertion, with post-operative sore throat in $1(3.33 \%)$ patient after 24 hours of surgery. LMA supreme can be considered as preferred choice of airway for elective surgeries under general anaesthesia.

\section{REFERENCES}

[1]. Dorsch, Jerry A. anaesthesia equipments. understanding anaesthesia equipments. s.1. : 5th edition, page number 462, 2012.

[2]. The advantages of the LMA over the tracheal tube or facemask: a meta-analysis. J., Brimacombe. 11, s.l. : Canadian Journal of Anaesthesia, 1995 Nov, Vol. 42. :1017-23..

[3]. Laryngeal Mask aiirway instruction. Brain A, Denman WT, Goudsouzian NG. San diago :s.n.

[4]. The Laryngeal Mask--an overview. Leach AB, Alexander CA. s.l. : European journal of anaesthesiology, 1991, Vol. 4. 19-31.

[5]. Laryngeal mask airway and the ASA difficult airway algorithm. Anaesthesiology. JL., Benumof. (3), s.1. : The Journal of the American Society of Anaesthesiologists, 1996 Ma, Vol.84. :686-99.

[6]. The laryngeal mask: a new concept in airway management. AIJ., Brain. 55, s.1. : . Br J Anaesth, 1983. :801-805.
[7]. Nasogastric tube insertion in anesthetised, intubated adult patients: A comparison between three techniques. al, Mohanchandra Mandal et. s.l. : Indian Journal of Anesthesiology, 2018, Vol. 117.

[8]. Comparison of the LMA Supreme vs the i-gel in paralysed patients undergoing gynaecological laparoscopic surgery with controlled ventilation. al., 9.W. H. L. Teoh et. 65,2010. 1173-1179.

[9]. Crossover comparison of the laryngeal mask supreme and the i-gel in simulated difficult airway scenario in anesthetized patients. Theiler LG, Kleine-Brueggeney M, Kaiser D, et al.2009, Vol. 111. 55-62.

[10]. Comparative evaluation of supraglottic airway devices i-gel versus lma- supreme in patients undergoing surgery under general anaesthesia. al, Vikas Gupta et. (2), s.l. : Indian Journal of Clinical Anaesthesia, April - June 2015, Vol. ;2. :86-91.

[11]. LMA Supreme and I-gel--a comparison of insertion success in novices. Ragazzi R, Finessi L, Farinelli I, et al. 67, 2012. :384-8.

[12]. A comparison of i-gel and LMA Supreme in anesthetized and paralyzed Children. Hyuk Kim et al. 5, s.l. : Korean journal of anesthesiology, November 2014, Vol. 67. 317.

[13]. A Preliminary Study of I-Gel:A New Supraglottic Airway Device. Ashish Kannaujia et al.(1), s.l. : Indian Journal of Anaesthesia, 2009, Vol. 53. :52-56.

[14]. Randomised comparison of the LMA Supreme ${ }^{\mathrm{TM}}$ with the I-Gel ${ }^{\mathrm{TM}}$ in spontaneously breathing anaesthetised adult patients. 26. Chew E F, Hasim N H, Wang C Y. 38, s.l. : Anaesth Intensive Care, 2010. 1018-1022. 